MATEC Web of Conferences 53, 02005 (2016)

DOI: $10.1051 /$ matecconf/20165302005

(C) Owned by the authors, published by EDP Sciences, 2016

\title{
Reconstruction of the Historical Heritage (Based on the Example of Azerbaijan Hamam)
}

\author{
Grigoriy Garmanov ${ }^{1, a}$, Mikhail Volkov ${ }^{1}$ and Tatiana Spiridonova ${ }^{1}$ \\ ${ }^{1}$ St. Petersburg State Polytechnical University, Politekhnicheskaya, 29, Saint-Petersburg, 195251, Russia
}

\begin{abstract}
The article discusses the history and features of recovery of Azerbaijan hamams. Restoration of the traditional architecture with the reference to the history is considered to be a significant factor for the national culture of Azerbaijan. The history of the hamams are reviewed in this article. The impact and importance of hamams in the development of settlements has been analyzed in this document. Besides aforesaid topics, the issue deals with the reconstruction and rehabilitation of hamams.
\end{abstract}

\section{Introduction}

Restoration of the traditional architecture with the reference to the history is considered to be a significant factor for the national culture conservation against the background of the modern massive development of the city of Baku, the capital of Azerbaijan [1, 2]. Among the historical buildings as well as prominent constructions preserved within the territory of the Absheron peninsular hamams appear to be of interest. Hamams are traditional public baths closely related to the lifestyle of the Azerbaijan population [3].

Hamams are quite often located near hieratic constructions due to requirements and peculiarities of the Muslim religion having such rituals which can be associated with washing and a number of other procedures [4].

\section{Hamams arrangement in a settlement planning structure}

As cultural and social buildings hamams were widely spread on the Absheron peninsular both in populated inhabitant places and garden areas where the basic population of Baku moved to adjacent settlements from April up to November (Figure 1).

Hamams arrangement in a settlement planning structure is caused by people's attraction to hieratic centres. These interrelated complementary objects form volumetric and spatial image of the Absheron settlements. Many hamams were built on the Absheron peninsular back in the medieval ages but a few of them have been conserved up to nowadays. There is a hamam of the year of 1388 in the settlement of Nardaran among them [2].

Archaeological and Ethnographic Museum Complex Gala contains many interesting examples hamams (Fig. 2-3). In the village of Gala and the adjacent territory, there are 215 archaeological sites. There remained a historical context, referring to the III millennium century BC In the village of Gala

${ }^{\text {a } C o r r e s p o n d i n g ~ a u t h o r ~: ~ g r i . g a r m a n o v @ g m a i l . c o m ~}$ 
are 5 mosques, 3 hamam (bath), houses, buildings, agricultural lands, tombs, mausoleums, burial mounds, remains of the fortress, have not lost their historical significance to the III millennium XX century.

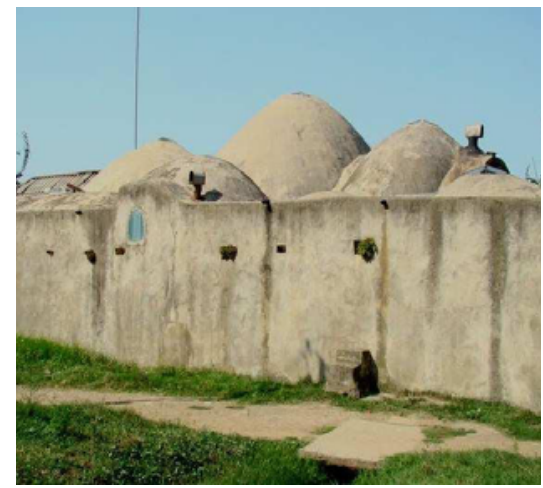

Figure 1. Hamam. Boradigah, Azerbaijan.

In 2008, on the initiative and under the direct supervision of the Heydar Aliyev Foundation in the territory of Archeology and Ethnography Reserve Gala was created "first Historical-Ethnographic Museum Complex under the open sky." The complex has collected and restored monuments of architecture found on the Absheron Peninsula [5-7]. (Figure 2, 3)
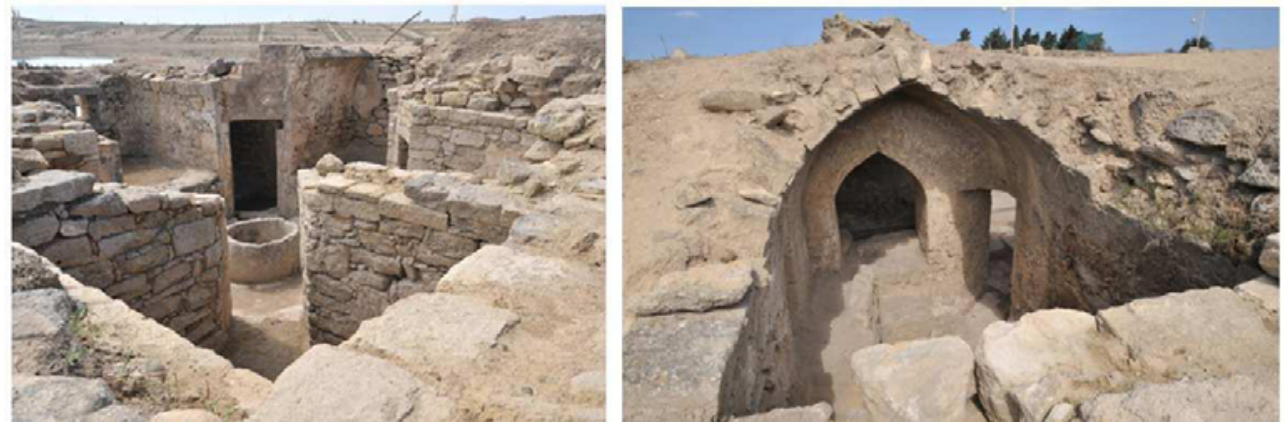

Figure 2. "Gum hamam" ("sand bath"), Azerbaijan. Figure from [7]
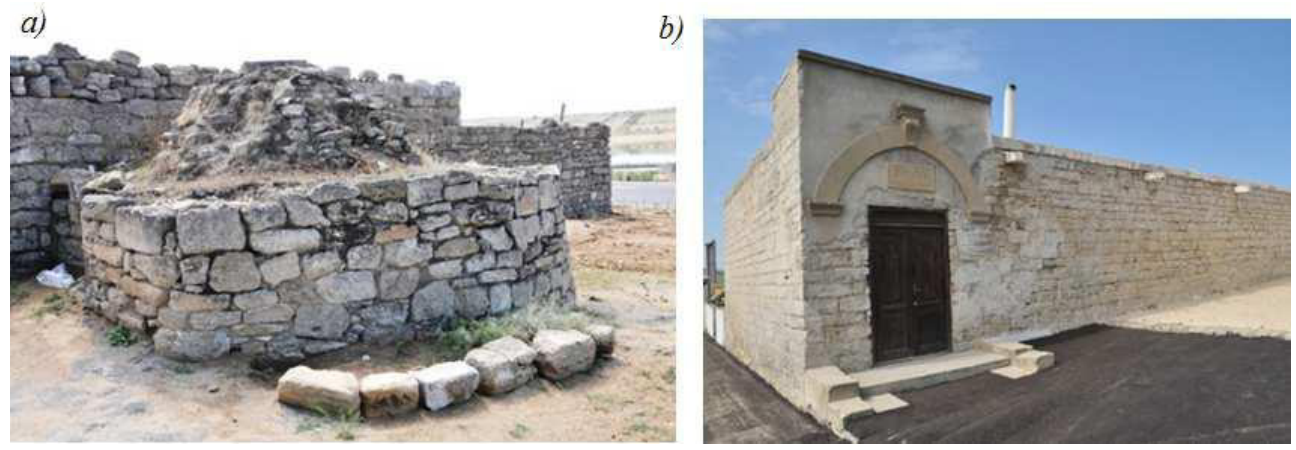

Figure 3. a) "Shore hamam" ("salt bath") b) "Bej hamam", Azerbaijan.. Reconstruction made in 1881. Figure from [7]

There was basic construction of hamams at the turn of XIX - XX centuries when the settlements became economically developed and population increased. It is an important period in the history of the Absheron settlements development where inhabitants were engaged into oil boom and took advantage of economic challenges for construction of hamams and other social and public constructions. It was that very time when hamams stated to play a significant role in settlements 
planning and development [8-10].

As to city planning hamams have their own peculiarities defined by their specific location. Land plots, where hamams are located, are quite varied. Volumetric and spatial system of hamams was elicited depending on their location [3].

The general trend in hamams arrangement lies in striving for making this large-scale construction significant and highlighting the fact it is a social and public building. It's quite important in the context of typical traditional solid fences and walls of private housing. Hamams show specifics of public constructions in mass development meeting the requirements for construction site management with due account for water supply sources (water wells, water reservoirs, open pools) and heat supply sources as well (storage pits for keeping oil and etc.).

Certain approaches of hamams arrangement on the construction sites in relation to street network have been found due to investigation of the existing hamams. This has afforded ground for their initial classification $[11,12]$. The most popular approaches of hamams arrangement can be the following ones:

1) hamams take active planning nodes and become dominant in construction development;

2) hamams are located in the through streets of a settlement;

3) hamams in a row development;

4) hamams in the outskirts.

All this contributed to bringing hamams to the positions of the significant civil facilities as well as hieratic objects [4-6].

\section{Types of Hamam volumetric layouts}

The volumetric layouts of Absheron hamams have been developing under the traditional functional pattern: entering room, dressing room, intermediate passing chamber for keeping heating regime between dressing and bathing rooms, 'hazna' (storage for hot and cold water).

There are 4 types of the Absheron hamams.

Considerable areas to ensure capacity for a large number of visitors were offered in the first type. This can be achieved by increasing a span between longitudinal walls resulting in big costs and technical complications. Four columns were set up in the central part in dressing and bathing rooms that allowed for $9.36 \mathrm{~m}$ to $12.80 \mathrm{~m}$ in length. The length of hamams normally reached $30 \mathrm{~m}$.

The second type of the Absheron hamams was more popular than the previous one. Keeping basic layouts points and technical approaches of the first type hamams the second type has its own architecture and composition features as well as volumetric spatial ones.

The hamams of this type with extended length had fixed rectangular shape and were clearly split into supplementary and main ones according to their layouts. The dominating elements of the hamams were the following: dressing and bathing rooms were the halls with joint space, having no intermediate supports, with non-deep enclaves along the axis. The rooms in the layout formed a shape of a cross; the corners were actual supports bearing under-dome space.

The third type of the hamams had layouts with displaced longitudinal axis relatively to dressing and bathing rooms. But its technological working cycle associated with water supply an

The constructions which have complex and combined layouts with independent volumetric and spatial rooms can be related to the fourth type.

The dressing room was represented in a whole volume under a relatively large dome, and bating room was split into parts on the internal network of the aisles owing to central supports gaining the dome of a small size. Such volumetric and spatial solution made it possible to use varied methods which combined basic composition elements. In this context we may compare the type under consideration with the previous one where an axial line of the hamam layout was displaced and volumes became more dynamic. According to this classification all the types given herein can vary significantly in the context of both layouts and volumetric and spatial solutions, as well as of construction approaches and decoration elements [13-15].

The Absheron hamams have been developing throughout the last century contributing to certain architectural and planning approaches which were specified in the classification given. This 
classification makes it possible to elicit all the general relations in the hamam construction evolution giving a wide range of the various types of buildings. Regardless the fact there is quite a definite typology there are no similar hamams. Each hamam has its own features. Conserving as well as research and contemporary use Absheron hamams is an integral part of the architectural heritage and civil culture. (Figure 4)

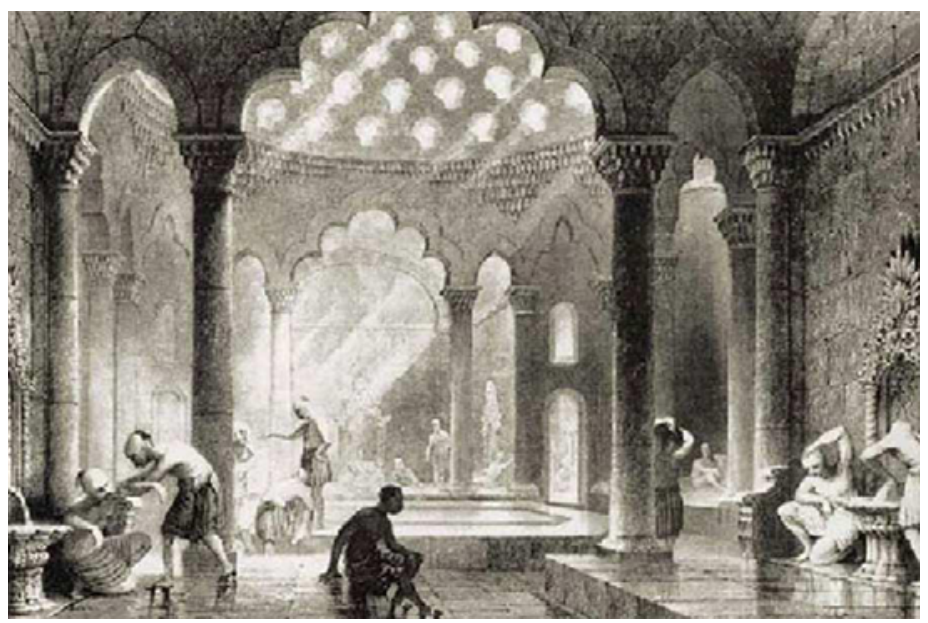

Figure 4. The medieval hamam. Engraving

\section{Temperature and humidity regimes of Hamams}

The most important element of hamams requiring specific concern when reconstructing and repairing objects is a conventional and historically developed heating and ventilation supply system. Historical heating and natural ventilation methods ensured a unique microclimatic regime in rooms.

The creators of hamams 'tuned' internal microclimate in the rooms as if it was a musical instrument'. An attempt to connect hamams to contemporary engineering networks inevitably leads to a temperature and humidity regime violation.

When making restoration and reconstruction works for this type of construction architectural layouts, construction features and unique temperature and humidity regime in the rooms must be considered. Since hamams have quite a complicated engineering system, which can be restored or rebuilt on the basis of the customs and experience, a reasonable engineering estimation appears to be a must and an evident issue.

The traditional heating and ventilation systems meant for hamams is a basic construction component. And along with that construction materials underwent a special attention. The builders of those times selected specific waterproof limestone that played a great role when exploiting hamams over several centuries. At the same time construction materials had to meet all the hygienic and esthetical requirements.

\section{Summary}

The territory of Azerbaijan is rich in archaeological sites, proving belonging to ancient settlements. From the standpoint of historical monuments Absheron Peninsula is of particular value.

The hamams within the Absheron territory are presented by a varied range of architectural layouts and construction approaches. This makes the grounds for an assumption that they can be distributed to other areas with due account for research and restoration and maintenance experience.

The unique heating and water supply system assigned for hamams called for quite a complicated individual «setting up» based on the experience and long life traditions. There are many cases of upgrading hamams and using modern methods to ensure water supply, heating and ventilation, as well 
as new construction materials which have finally resulted in deteriorating of historically developed functioning system applied in these objects. Restoration of hamams is a complex research and practical issue nowadays.

Regretfully these interesting civil and social facilities, which were an important part of local settlement development, have lost its significance in our days. In many cases these land plots are still idle and empty giving an example of descendants' neglect regarding their national architectural and cultural heritage.

There are about $50 \%$ of hamams remained on the Absheron peninsular. And they make it possible to evaluate their significance as civil architexctural monuments having a large scope of shapes and volumes.

It's also important to make them an integral part of city planning and state their contemporary significance in the settlement planning structures.

\section{References}

1. Dadashev, S., Usejnov, Arhitektura Azerbajdzhana 3 -19 vekov, (Stroyizdat, Moscow (1983)

2. Bretanickij, L.S. Salamzade. G. Istorija arhitektury Azerbajdzhana, (Stroyizdat, Moscow (1963)

3. Fatullaev-Figarov, S.S., Zodchestvo Apsherona. Issledovanija zamkov, mechetej, hamamov, ovdanov, karavan-saraev, djevjelikov, mavzoleev i vill Apsherona, (Stroyizdat, Moscow (2003)

4. Fatullaev-Figarov, S.S. Gradostroitel'stvo i arhitektura Azerbajdzhana 19 - nachala 20 veka, (Stroyizdat, Moscow (1986)

5. Alihodzic, R., Applied Mechanics and Materials, 680, 494-498 (2014)

6. Huseynov, F. E. Oglu, Procedia Engineering, 21, 534-542 (2011)

7. http://www.trend.az/life/history/1932698.html date accessed 18.10.2014

8. Innovative Technologies in Development of Construction Industry 10.4028/www.scientific.net/AMM.725-726

9. Azerbaijan Hamam, the History and Restoration Specifics 10.4028/www.scientific.net/AMM.725-726.1079

10. N. Lipovac, A.M. Jandriček, Prostor, 19 (2), 443-455 (2011)

11. N. Lipovac, Prostor, 19 (1), 2-17 (2011)

12. N. Lipovac, Prostor, 18 (2), 268-287 (2010)

13. Lipovac, Prostor, 5 (1), 1-33 (199

14. Čerpes, N. Pandol, A. Fikfak, European Countryside, 6 (3), 225-242 (2014)

15. C. Zappulla, C. Suau, A. Fikfak, Journal of Architecture and Urbanism, 38 (4), 247-264 (2014) 